\title{
Modeling Price Volatility for Selected Agricultural Commodities in Ethiopia: The Application of GARCH Models
}

Tirngo ( $\nabla$ ttdinku@gmail.com )

Bahir Dar University

\section{Research Article}

Keywords: price volatility, Agricultural commodities, GARCH, TGARCH, EGARCH

Posted Date: June 30th, 2021

DOl: https://doi.org/10.21203/rs.3.rs-664913/v1

License: (c) (1) This work is licensed under a Creative Commons Attribution 4.0 International License.

Read Full License 


\title{
Modeling Price Volatility for Selected Agricultural Commodities in Ethiopia: The Application of GARCH Models
}

\begin{abstract}
s
The purpose of this study was to model and forecast volatility of returns for selected agricultural commodities prices using generalized autoregressive conditional heteroskedasticity (GARCH) models in Ethiopia. GARCH family models, specifically GARCH, threshold generalized autoregressive conditional heteroskedasticity (TGARCH) and exponential generalized autoregressive conditional heteroskedasticity (EGARCH) were employed to analyze the time varying volatility of selected agricultural commodities prices from 2011 to 2021. The data analysis results revealed that, out of the GARCH specifications, TGARCH model with Normal distributional assumption of residuals was a better fit model for the price volatility of Teff and Red Pepper in which their return series reacted differently to the good and the bad news. The study indicated the presence of leverage effect which implied that the bad news could have a larger effect on volatility than the good news of the same magnitude, and the asymmetric term was found to be significant. Also, TGARCH model was found to be the accurate model for forecasting price return volatility of the same commodities, namely Teff and Red Pepper. In short, the study concludes that TGARCH was to be the best fit to model and forecast price return volatility of Teff and Red Pepper in the Ethiopian context.
\end{abstract}

Key terms: volatility, price, Agricultural commodities, GARCH, TGARCH, EGARCH

\section{Background of the study}

A market by its nature is dynamic and fluctuating (Pindyck, 2001), and it can be impacted by several forces such as human emotions, prices, behaviors of producers, and consumers. Specifically, a market in developing countries, including Ethiopia, is often characterized by a low trading volume, lack of competition, and high price volatility (Abebe et al, 2020) by which a low trading volume implies that the quantity and quality of information that buyers receive are limited, 
and thus the price prediction process could be faulty which again brings about inefficient market systems (Mattos \& Giarcia, 2004).

It is obvious that volatility has put great pressure on the struggle made to reduce poverty. Both the developing economies of many countries and governments remained highly dependent on commodity productions for growth and export, and governments regularly distribute food grains at subsidized prices to their people to fight poverty (Chen, Rogoff, \& Rossi, 2010).

Indeed, market volatility is a significant issue which needs attention, for commodity market volatility shows a rising trend in prices ((Arezki, 2012); (Rezitis \& Sassi, 2013), and it implies the existence of hazardousness.

According to IMF (2007), since 2006 food prices have risen by $45 \%$ which evidences the existence of dramatic price growth of agricultural products; many price increments have gone beyond their normal limits; for example, the prices of crude oil, tin, nickel, soybeans, corn, and wheat are citable. The rapid growth of prices were, specifically, observed in the main food crops such as corn, wheat, and edible oil even if the raise is true in other food crops including rice (Jema, Fekadu, Wagayehu \& Girmay, 2011).

Specifically, in Ethiopia, since the end of 2005 food prices have shown dramatic increments. For instance, in 2006, 2007, and 2008, successive increments have been recorded as $15.1 \%$, 28\%, and $57.4 \%$, respectively; the dramatic growth in agricultural commodity prices has remained not only an issue of policymakers, donor agencies, and economists but also the concern of the society at large (Jema, Fekadu, Wagayehu \& Girmay, 2011) including researchers. This means that food price in Ethiopia has not shown stability. Regarding this, Hilegebrial (2015) explained that although food price inflation has shown a stable growth rate in the first quarter of 2010, starting from the third quarter of 2010 up to the second quarter of 2012, it showed high annual food inflation rate which was transformed from single digit to double digit. Zewdu (2016) further explained that this trend continued, and food inflation demonstrated the highest growth rate from February 2011 and reached its highest growth of 51.7\% in October 2011; the food inflation level demonstrated an increment trend from November 2014 till May 2015 which was rated as 10\%. 
Hence, food inflation has shown more volatile trends than non-food inflation, and it has taken also a lion's share of the volatility of headline inflation (Zewdu, 2016).

As a change in prices of agricultural products become a global phenomenon (Shiferaw, 2012), price volatility in markets of major cereal crops remains high in Ethiopia too (Rashid, 2010). In line with this conception, although agricultural products market policies in Ethiopia have tried to make dramatic changes over the past years, the desired outcomes have not been achieved, and the efforts made to reduce price volatility have remained unsuccessful (Shiferaw, 2012). Thus, it is crucial to continue the effort with this regard, and thus develop an appropriate tool which can accurately model and forecast the agricultural commodities prices. An accurate prediction of future food price increment conditions is a crucial planning tool for the government, investors, farmers, traders and food aid institutions in Ethiopia; in fact, an accurate evaluation of agricultural commodity price movements is important for inflation control and production planning, and it is particularly valuable to developing countries, like Ethiopia, which is in the process of promoting investment in the agriculture sector, and which is working hard for poverty reduction (Chen, Rogoff, \& Rossi, 2010).

\section{Literature Review}

Volatility refers to changes in economic variables over time; in a strictly descriptive context, it is a measure of market different from the previous period to the current period. It is a measure of price variation from the previous period to the current period; it is not crucial to note that variation is always problematic; for example, when prices move along a smooth and well-established trend reflecting market fundamentals and well known seasonal patterns (Shiferaw, 2009). But price variations become problematic when it is large and become unpredictable and, consequently, create a level of uncertainty which increases risks for producers, traders, consumers and governments and may lead to sub-optimal decisions (Shiferaw, 2009).

Price variations are measurable. And there are two commonly used volatility measures: realized volatility and implied volatility where the former is computed from historical prices which use past history to predict the future, and the latter is computed from the market's consensus of the fair value for a derivative instrument such as the S \& P500 index option contract, and it is a "forward" 
looking or "future" expectation estimate. Historical volatility described by Brook (2002) involves the calculation of variance or standard deviation of returns in the usual statistical way over some historical period and this may become a forest of all future periods.

The evolution of price fluctuation was originated from Markowitz's (1952) paper which focused on the concept of the uncertainty of asset prices that is based on price movement and dynamics, and according to Mandelbort (1963), volatility clustering and leptokurtosis are the main characteristics of financial time series among others.

Traditional econometric models assume a constant one-period forecast variance. Engle (1982) was the pioneer in developing volatility models in which his work was dealing with changing variance using the autoregressive conditional heteroskedasticity $(\mathrm{ARCH})$. These are mean zero, serially uncorrelated processes with non-constant variances conditional on the past, but constant unconditional variances (Abebe et. al, 2020). For such processes, the recent past gives information about the one-period forecast variance. The basis of an ARCH model is that there is time varying mean (hetroschdastic) that depends (conditional) on lagged effect; hence large and small errors tend to cluster together when a big shock occurs in the previous period; it is more likely that the variance of the current period will also be bigger and vice versa (Abebe et. al, 2020).

Various models brought into volatility modeling after Engle's (1982) Autoregressive conditional heteroskedasticity $(\mathrm{ARCH})$ come into effect. An extension of Engle's ARCH model was introduced four years later by Bollerslev (1986), and this is a generalized version called generalized autoregressive conditional heteroskedasticity (GARCH) model, followed by exponential generalized autoregressive conditional Heteroskedastic (EGARCH) model (Nelson 1991), Threshold generalized autoregressive conditional Heteroskedastic (TGARGH) (Zakoian, 1994) and others became dominant in modeling conditional variance and risk prima.

In the Engle's ARCH (q) model, the conditional variance is specified as a linear function of past sample variances large past square returns which imply a large conditional variance for the return. However, the ARCH model treats positive and negative returns in the same way and is very restrictive in parameters only whereas the $\operatorname{GARCH}(\mathrm{p}, \mathrm{q})($ Bollerslev, 1986) model allows lagged conditional variances to enter into the model as well, in which conditional variance being 
expressed as a linear function of past squared innovations and of its past values, providing the non-negativity constraint. The GARCH model assumes only the magnitude but not the positivity or negativity of unanticipated excess returns that determines feature variance. To overcome this weakness in the GARCH model Nelson (1991) proposed the EGARCH to allow for asymmetric effects. The EGARCH model consents positive and negative shocks of equal size to have different impacts on volatility which means negative shocks at time $\mathrm{t}-1$ have a stronger impact on the variance at time $\mathrm{t}$ than positive shocks (Nelson, 2011) because, the increase in risk was believed to come from the increased leverage induced by a negative shock.

The other model comparable to the Exponential GARCH model, in allowing asymmetric shocks to volatility is the Threshold GARCH model, in which volatility tends to increase with bad news and decrease with good news and it is introduced by Zakoian (1994). Some of the differences in these two models are that the TGARCH makes volatility a function of non-normalized innovations and provides additive modeling, while EGARCH does not. In modeling asymmetries, EGARCH imposes a constant structure at all lags whereas, different lags may yield contrary contributions in TGARCH cases. Though most of these volatility models originated from the financial market perspective a long time ago, and academia abundantly goes far in modeling volatility of different financial time series, its application was scant in analyzing the volatility behavior of agricultural commodities.

Nowadays, increasing demand to make use of GARCH family models has come into exercise as a result of continuous fluctuation in commodities prices. The agricultural commodity market reacts more to positive news than negative news where speculative hoarding takes place (Thiyagarajan et al., 2015). According to Thiyagarajan et al (2015), GARCH $(1,1)$ and for the asymmetric modeling P GARCH $(1,1)$ were found to be the best models; for example, for the Indian and for the asymmetric modeling as they explain volatility better in their category as the calculated LM test values are least for them signaling that these models are better in capturing the effect of volatility, than others, in the Indian agricultural market; agricultural commodity market quantities and prices are often random which introduces a large amount of risk and uncertainty into the process of market modeling and forecasting. 
Also, the volatility in the prices of commodities has a direct impact on final consumers as the price of food is impacted by production costs as well as by inflation (Roux, 2018). Commodities can be used as financial assets in various forms, and understanding the volatility present in the price could be used to the advantage of the investor (Roux, 2018). Le Roux (2018) empirically analyzed the GARCH family models; the generalized autoregressive conditional Heteroskedastic (GARCH) model, the Glosten - Jagannathan-Runkle generalized autoregressive conditional Heteroskedastic (GJR-GARCH) model, and the exponential GARCH (EGARCH) model to identify the best fitting model to selected agricultural commodities. The results suggest that volatility is present in the data; overall, GARCH was the best fitting model for the S\&P GSCI agriculture index during and after the financial crisis and EGARCH for the Brazilian Real and only the GJR-GARCH results for cocoa indicated the existence of leverage effects.

Moreover, the study conducted by Adugh (2019) and which focused on modeling volatility of agricultural commodity by using monthly commodity food price index data in Nigeria showed ARMA $(2,1)$-GARCH $(1,1)$ and ARMA $(2,1)$-EGARCH $(1,1)$ models with student-t innovations were appropriate in describing the symmetric and the asymmetric behaviors of the log returns. In fact, many scholars has employed GARCH family models in order to model volatility of agricultural commodity price indexes by using data from a variety of sources which can be obtained from both developed and developing countries and at different times. However they found a different model which fits best to model agricultural commodity prices index. Therefore, this study attempted to add its contribution in modeling volatility of selected agricultural commodities using data from Amhara National Regional State Trade and Market Development Bureau (ANRSTMDB) to examine the best fit GARCH family model.

Statement of the problem

Commodity prices are characterized by a high degree of volatility (UNCTAD, 2019), and the worst is that the problem becomes serious in commodity dependent developing countries like Ethiopia. In such countries, agricultural products are major contributors to food price volatility which, in turn, makes very difficult to ensure food security with the presence of unstable price in these products. As the agriculture sector is the mainstay of Ethiopia's economy, modeling volatility is highly demanding for investment decisions and policy recommendations and forecasting. 
Accordingly, using a model which can help to measure the volatility of price indexes (Engle 1982, Zakoian 1994, Bollerslev 1986, Zakoian 1994) serves as an insight to predict volatility. In line with this, Lama et al. (2015), Le Roux (2018), and Adugh (2019) are pioneers who model volatility specifically on agricultural commodity prices.

According to Lama et al. (2015), most of the agricultural price series can be modeled as time series data where the information is collected over time at equal time-epochs. In this framework, Lama et al. (2015) studied the autoregressive integrated moving average (ARIMA) model, generalized autoregressive conditional Heteroskedastic (GARCH) model and exponential GARCH $(\mathrm{EGARCH})$ model along with their estimation procedures for modeling and forecasting of three price series, specifically domestic and international edible oils price indices and the international cotton price 'Cotlook A' index. Their study revealed that the EGARCH model outperformed the ARIMA and the GARCH models in forecasting the international cotton price series primarily due to its ability to capture asymmetric volatility patterns.

Through the use of 26 years of monthly time series data on the Commodity Food Price Index, Adugh (2019) also models volatility of agricultural commodity to searches for optimal Autoregressive Moving Average and Generalized Autoregressive Conditional Heteroskedasticity (ARMA-GARCH) models. According to his study, ARMA $(2,1)-G A R C H(1,1)$ and ARMA $(2,1)$ EGARCH $(1,1)$ models were fitting in describing the symmetric and asymmetric behaviors of the $\log$ returns which could describe best the log returns price volatility of selected agricultural commodity food products in Nigeria. The study further showed that the best fitted models were not necessarily the best forecast models; price volatility was found to be quite persistent and mean reverting in all the estimated GARCH models indicating that past volatility was important in forecasting future volatility, there existed a leverage effect in the log returns suggesting that negative shocks had more impact on volatility than positive shocks of the same magnitude.

Furthermore, by analyzing the GARCH family models, Le Roux (2018) suggested that volatility was present in the data, overall, GARCH was the best fitting model for the S\&P GSCI Agriculture Index during and after the financial crisis and EGARCH for the Brazilian Real and only the GJRGARCH results for cocoa indicated the existence of leverage effects. 
With special reference to the context of Ethiopia, researchers, for example, Shiferaw (2012), Ayele, Gabreyohannes, and Tesfay (2017), Muanenda \& Yohannes. (2018), Abebe, (2020) have conducted studies which focused on modeling commodity price volatility. Shiferaw (2012), in his study on selected agricultural products in Ethiopia, found that the Autoregressive Conditional Heteroskedasticity $(\mathrm{ARCH})$ and Generalized $\mathrm{ARCH}(\mathrm{GARCH})$ models were appropriate. In line with this, the results suggested that $\operatorname{GARCH}(1,1), \operatorname{GARCH}(1,2)$, and $\operatorname{GARCH}(2,1)$ models were the most appropriate fitted models that a researcher could use to evaluate the volatility of the log-returns of the price of cereal, pulse and oil crops, respectively. Price volatility was persistent in all three categories (cereal, pulse and oil crops) of selected agricultural goods. Ayele, Gabreyohannes, and Tesfay's (2017) study revealed that the GARCH-M $(2,2)$ was found to be the best fit model for modeling and forecasting the gold price volatility in the Ethiopian market and Muanenda and Yohannes (2018) found that $\operatorname{ARIMA}(0,1,1)$ and $\operatorname{ARMA}(2,2)-\operatorname{GARCH}(2,1)$ with the normal distributional assumption for the residuals were adequate models for modeling and forecasting the volatility of the export price of Sesame in Ethiopia. Moreover, recently, Abebe, (2020) also conducted a study on modeling time-varying coffee price volatility in Ethiopia, and he found that the multiplicative GARCH-MIDAS model provided an explanation for stylized facts that could not be captured by the standard GARCH model.

Getnet's (2009) study which focused on prices of export commodities that were subject to extreme volatility with considerable impact on the level of uncertainty used daily and monthly export price data. But, as it is observed from the literature, no one best model fits for all data series because of the different structures of markets and nature of commodities.

In conclusion, studies by Muanenda and Yohannes (2018) and Abebe (2020) focused on single commodity sesame and coffee, respectively where each of them is export commodity. Export commodities usually experience special price volatility than other commodities traded in the domestic market, as it is also driven by the world supply and demand. Data used by both Muanenda and Yohannes (2018) and Abebe (2020) was an export price, where prices of export commodities are subject to extreme volatility (Getnet 2009) with considerable impact on the level of uncertainty. On the one hand, as it is understood from the literature, there is no one best model which fits for all data series and the nature of the commodity. Thus this study tried to add its contribution to documenting the best fit volatility model for the selected agricultural commodity price in Ethiopia 
with the use of monthly retail price data. In other words, it attempted to fill the aforementioned gaps which are related to modeling the best fit volatility model used to forecast prices agricultural commodities with the use of agricultural commodities retail price data in Ethiopia. In line with these conceptions, the general objective of the study was to model and predict price volatility for selected agricultural commodities in Ethiopia. Specifically, it aimed to identify the best fit model of the GARCH Family models and predict price volatility of agricultural commodities in Ethiopia.

\section{Research Methodology}

In the present study, a time series data on the prices of agricultural commodities, specifically, average monthly retail prices data of Teff and Red Pepper which were recorded from the year 2010/11 up to 2020/21 were taken from Amhara National Regional State Trade and Market Development Bureau (ANRSTMDB). The reasons for selecting Teff and Red Pepper are twofold: the first one is the availability of data, and the second reason is the relative importance of the two commodities in the daily consumption of the country and their increasing demand worldwide. That is, Teff is one of the most important commodities for farm income and food security in Ethiopia which accounts for the largest share of the cultivated area and the total value of cereal productions (Zinabu Tesfaw 2021; CSA, 2019), it is also supposed to be the next super-grain and Injera could be the next super-food in the globe (Fikadu et al., 2019). Similarly, red pepper is the essential spice for Ethiopian food. Injera could not be used without wot which uses red pepper as its main ingredient.

\section{Model selection}

Financial time series evidenced different stylized facts such as leptokurtic, volatility clustering and leverage effect (Frank et al. 2011). Leptokurtic refers to the inclination for a series to get back to have disseminations that display fat tails and peaked at the mean. Volatility clustering indicates that a large shock tends to be followed by a similar large stock, and a small shock tends to be followed by a similar small stock, and leverage effect signifies a negative correlation between an asset return and its changes of volatility and the leverage effect. High frequency data often have also a property of long memory; as a result, it is essential to model such a high frequency financial time series data to study the effect of current return shocks on future expected volatility. In 
financial studies, instead of the actual price values, it is common to analyze log return series, for its better statistical properties. The log return series is, therefore, written as:

$$
\mathrm{Yt}=\ln (\mathrm{pt} / \mathrm{pt}-1)
$$

Where: $\mathrm{p}_{\mathrm{t}}$ is average monthly price of a commodity at period $\mathrm{t}$

$\mathrm{Y}_{\mathrm{it} \text { - }}$ is $\log$ returns series of a commodity at period $\mathrm{t}$

\section{Unit Root Test for Non-stationary Series}

A unit root is a stochastic trend in a time series. In order to run a time series data analysis, it is compulsory to test stationarity of the data. In this study, Augmented Dickey-Fuller (ADF) unit root test was used to check the stationarity.

When there is more than one adequate model, a valid criterion is needed for model selection. In this study, Akaike information criterion (AIC) and Schwarz information criteria (SIC) were applied for the model selection purpose.

$$
\begin{aligned}
& \mathrm{AIC}=-2 \ln (\mathrm{L})+2 \mathrm{k} \text { and } \\
& \mathrm{BIC}=-2 \ln (\mathrm{L})+\mathrm{k} \ln (\mathrm{T}),
\end{aligned}
$$

Where $\mathrm{L}$ is the maximized value of the likelihood function and $\mathrm{k}$ is the number of (free) parameters in the model (i.e., $\mathrm{k}=\mathrm{p}+\mathrm{q}+1$. The model with the minimum AIC and BIC value is taken as the best-fit model (Brockwell \& Davis, 2009; Burnham \& Anderson, 2002). Moreover, The BreuschGodfrey (Godfrey, 1996) and Jarque-Bera test (Jarque and Bera, 1987) tests were also applied to test for serial correlation and normality, respectively.

\section{GARCH component Model specifications}

\section{Autoregressive Conditional Heteroskedastic ARCH model}

An ARCH model is an important tool in analyzing a time series data, predominantly in financial applications which is originally proposed by Engle (1982). It could help to specify the conditional distribution of $\varepsilon$ t given the information available up to time $\mathrm{t}-1$. These models are especially useful when the goal of the study is to analyze and forecast volatility. 
The model is specified as;

$$
\begin{aligned}
& \mathrm{Yt}=\mu \mathrm{t}+\varepsilon \mathrm{t} \\
& \delta=\omega+\alpha_{1} \varepsilon^{2}{ }_{t-1}+\alpha_{2} \varepsilon_{t-2}^{2}+\alpha_{3} \varepsilon_{t-3}^{2}+\ldots .+\alpha q \varepsilon_{t-q}^{2}
\end{aligned}
$$

Where: $\varepsilon_{t}$ is the shock at time $\mathrm{t}, \boldsymbol{\delta}^{2}$ volatility at time $\mathrm{t}$ and $\varepsilon^{2}-1$ is squared innovation at time $\mathrm{t}-1$

\section{Generalized Autoregressive Conditional Heteroskedastic GARCH Model}

The generalized ARCH model developed by Bollerslev (1986). A Generalized Autoregressive Conditional heteroskedasticity process is said to be a GARCH (p, q) process, and the model is variance and covariance stationary where it imposes non negativity constraint for $\alpha, \beta$ and $\omega$

The model is being expressed as a linear function of past squared innovations and of its past values The basic $\operatorname{GARCH}(1,1)$ is expressed as;

$$
\delta=\omega+\alpha 1 \varepsilon 2 t-1+\beta \delta 2 t-1
$$

\section{Exponential Generalized Autoregressive Conditional Heteroskedastic (EGARCH) Model}

EGARCH is another volatility model proposed by Nelson (1991). This model is expresses as follows:

$$
\ln \delta=\omega+\beta \ln \delta 2 t-1+\alpha 1 \frac{|\varepsilon 2 t-1|}{\delta 2 t-1}+\gamma \frac{\varepsilon 2 t-1}{\delta 2 t-1}
$$

Where $\alpha$ represents the symmetric effect of the model, $\beta 1$ measures the persistence in conditional volatility shock. Large value of $\beta 1$ implies that volatility will take a long time to die out following a crisis in the market. The volatility shock is asymmetric when $\gamma \neq 0$, If $\gamma \neq 0$ then the model is symmetric (positive and negative shocks of the same magnitude have the same effect on volatility). When $\gamma<0$, it implies leverage effect exists and negative shocks (bad news) generate more volatility than positive shocks (good news) of the same magnitude and when $\gamma>0$, it implies that positive shocks generate more volatility than negative shocks of the same modulus.

\section{Threshold Generalized Autoregressive Conditional Heteroskedastic TGARGH}

The Threshold GARCH (TGARCH) model was proposed by Zakoian (1994) by which the model allows for asymmetric shocks to volatility that allows positive and negative shocks of equal size to have different impacts on volatility. 
Simple Threshold GARCH specified as:

$$
\delta=\omega+\alpha 1 \varepsilon 2 t-1+\beta \delta 2 t-1+\gamma \varepsilon 2 t-1 d t-1
$$

Where $\mathrm{dt}=1$ if is negative and 0 otherwise. In the TGARCH $(1,1)$ model, volatility tends to decreases with good news.

\section{Diagnostic check}

Necessary model diagnostic checking were employed; for the purpose of this study, the BreuschGodfrey serial correlation LM test was employed in order to check for possible ARCH effects on the residuals, Corrologram of standardized residual squared for serial correlation on the residuals and Jarque - Bera for normality tests for normality on the residuals

\section{Evaluation of forecasting accuracy}

The root mean square error (RMSE), mean absolute error (MAE), Theil inequality coefficient and mean absolute percent error (MAPE) were used in order to evaluate forecasting accuracy of the model.

\section{Result and Discussions}

One of the objectives of this study was to identify the best fit GARCH Family model. To meet this objective, average monthly retail prices data of Teff and Red Pepper from the year 2010/11 up to 2020/21 were taken and analyzed as follows:

For better understanding of the nature and distributional properties of the price return series, summary statistics such as monthly mean returns, maximum and minimum returns, standard deviations, skewness, kurtosis, and Jarque-Bera statistics for the commodity prices return were computed and presented as follows in Table 1.

Table 1: Descriptive statistics

Teff Price return

Mean

STDEV
0.648011234

4.796661932

\section{Red Pepper price Return}

0.756795985

32.64028781 
Minimum

Maximum

Skewness

kurtosis
$-26.57020333$

28.01798567

0.305050352

21.38342471
$-200$

204.2969073

32.64029

31.127

\section{Source: Author's own}

As it is shown in Table 1, the summary statistics indicates that the average monthly price returns of Teff and Pepper are $0.648 \%$ and $0.757 \%$, respectively, with a monthly standard deviation of 4.79 for Teff and 32.64 for pepper. These reflect high levels of dispersions from the average returns in the market over the period under review. The wide gaps between the maximum and minimum price returns give supportive evidences to the high level of variability of price changes in the market over the study period. The high kurtosis value of $21.38342471 \%$ for Teff and 31.127 for Red Pepper implying that big shocks of either signs are more likely to be presented in the series indicates that the returns series are clearly leptokurtic. The skewness coefficient of 0.305050352 and 32.64029 for Teff and Red Pepper, respectively, the null hypotheses of zero skewness and kurtosis coefficient of 3 are rejected at 1\% (0.01) significance level suggesting that the monthly price returns series for both of the commodities do not follow a normal distribution. The JarqueBera test also confirmed this rejection of normality in series since the associated p-value is far below $1 \%$ significance level.

Graphical properties of the price and return series, which is the first step in analyzing time series data, are plotted against time as follows. This could help to understand the trend as well as pattern of movement of the original series.

\section{Figure 1: Price series}



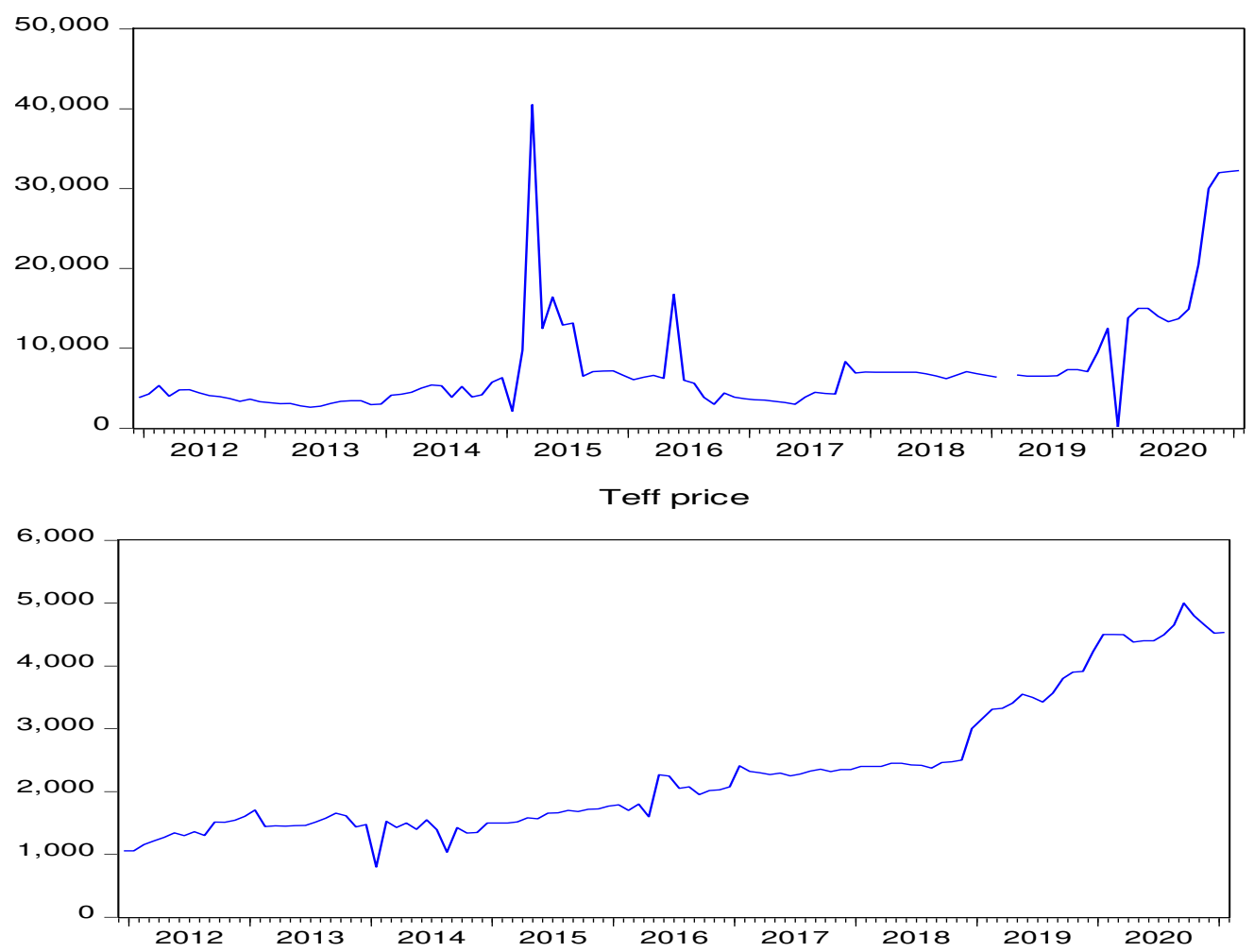

Source: Author's own

From the time plot of monthly Teff and Red pepper price movement, it is clearly seen that the trend movement in the plot is not smooth. This indicates that the means and variances of both the commodities are heteroskedastic and the series seems to be non-stationary. Transforming the monthly price data $\left\{Y_{t}\right\}$ to natural $\log$ returns $\left\{r_{t}\right\}$ is, therefore, made.

In addition, the plots of the commodities price returns as function of time are shown in the following figure. The time plot of price returns indicates that some periods are more risky than others. There is also some degree of autocorrelation in the riskiness of the log returns. The amplitudes of the price returns vary over time as large changes in returns tend to be followed by large changes and small changes are followed by small changes.

\section{Figure 2: Return series}



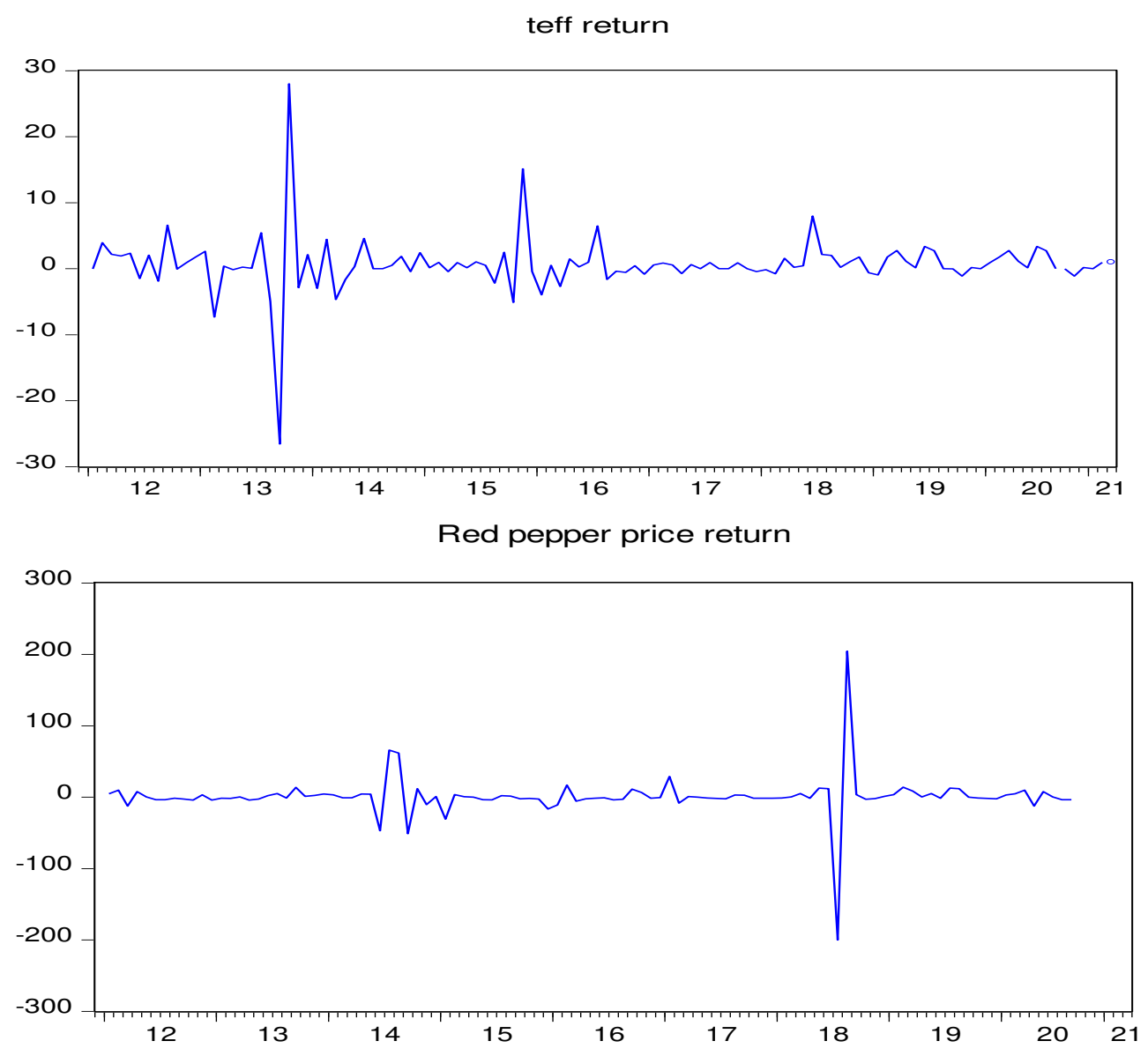

Source: Author's own

This is one of the stylized facts of the financial time series the so called volatility clustering. The volatility clustering in the series indicates that the returns are being driven by market forces. In order to meet the objective, GARCH family models were applied EViews 10 statistical package used to compute the estimates of the GARCH, volatility model parameters. In order to model price volatility, monthly price series for each selected commodity used to compute the logarithmic return series as $\mathrm{Yt}=\ln (\mathrm{pt} / \mathrm{pt}-1)$.

\section{Unit Root Test for Non-stationary Series}

For a time series data, one should check for stationarity in order to find an appropriate model. Therefore, in this study, Augmented Dickey-Fuller (ADF) unit root test was used to check the stationarity of the monthly natural log return series. The result is presented in Table 2. As it is 
observed from the table, the null hypothesis of unit root would be rejected; that is, the series are stationary at level.

Table 2. Unit Root Tests for the Series (at level)

ADF test

\begin{tabular}{llrr} 
Price return series & test equation & Test Statistics & P Value \\
Teff & With intercept & -8.443688 & 0.0000 \\
& With rend and Intercept & -5.902060 & 0.0000 \\
\multirow{2}{*}{ Red Pepper } & With intercept & -8.552758 & 0.0000 \\
& With rend and intercept & -8.538451 & 0.0000 \\
\hline
\end{tabular}

Source: The Author

Test of ARCH effect

Test of ARCH effect is one of the most important issue to be checked before applying GARCH models. LM test for the squared residuals of the fitted model proposed by Engl (1982) was conducted for testing heteroscedasticity.

Table 3: Hetroskedasticity test: ARCH

ADF test

Price return series F Statistics Chi square Statistics

Red Pepper

$\mathrm{ARCH}(1)$

5.24707

9.622873

(0.0072)

(0.0081)

Teff

$\mathrm{ARCH}(1)$

8.230019

7.723517

(0.0051)

$(0.0055)$

\section{Source: The Author}

Although the null hypothesis states that there is no remaining ARCH effect, the finding indicates the existence of ARCH effect in both commodities; in fact, the null hypothesis is rejected. Therefore, it is better to estimate the ARCH model for better result since it shows the variance of return series for each commodity is time varying. 


\section{GARCH component Model Specification}

After confirming the presence of $\mathrm{ARCH}$ effect in the residuals of the mean model, one needs to estimate GARCH model to test for the presence of asymmetry and time varying unconditional variance in the series. Various symmetric $(\mathrm{GARCH})$ and asymmetric (EGARCH, TGARCH) models for the price return series were considered. Then, for the model selection procedure, different symmetric and asymmetric GARCH models of different orders of $\mathrm{p}$ and q. were fitted for each series. Out of these symmetric GARCH model and Asymmetric EGARCH and TGARCH models under normal assumption for residuals were selected as possible models for the price volatility based on the Akaika information Criteria AIC and Schwarz criterion (SIC). Table 4 displays the summary results. Additionally, forecasting performance of the selected GARCH models is considered in the selection of the appropriate conditional volatility model.

Table 4: Model selection

\section{Information criteria}

\begin{tabular}{lllc} 
Series & Model & AIC & SIC \\
\hline Red pepper price return & GARCH 11 & 8.336949 & 8.413230 \\
& GARCH $(2,0)$ & 8.336940 & 8.413220 \\
& TGARCH $(\mathbf{1}, \mathbf{1})$ & $\mathbf{8 . 2 4 5 9 9 8}$ & $\mathbf{8 . 3 4 7 7 0 5}$ \\
& EGARCH $(1,1)$ & 8.351618 & 8.453326 \\
Teff price return & GARCH $(1,1)$ & 5.002132 & 5.075782 \\
& GARCH $(2,0)$ & 5.002132 & 5.075781 \\
& TGARCH $(\mathbf{1}, \mathbf{1})$ & $\mathbf{4 . 8 0 9 8 7 2}$ & $\mathbf{4 . 9 0 8 0 7 1}$ \\
& & & 4.937733
\end{tabular}


Based on the Akika information criteria (AIC) and Schwarz criterion (SIC), TGARCH model with normal distributional assumption performs better in describing volatility of Teff price return and Red pepper price return in Ethiopia under the years reviewed. The coefficients of the asymmetric terms are positive 3.091644 and negative 8.057376 for Teff price return and Pepper price return, respectively, and both are statistically significant at $1 \%(0.01)$ level.

The estimate of tie varying volatility is given as follows:

$\delta=\omega+\alpha_{1} \varepsilon^{2}{ }_{\mathrm{t}-1}+\beta \delta_{\mathrm{t}-1}+\gamma \varepsilon^{2}{ }_{\mathrm{t}-1} \mathrm{~d}_{\mathrm{t}-1}$

$\boldsymbol{\delta}_{\text {teffreturn }}=5.218448+0.01089 \boldsymbol{\delta}_{\mathrm{t}-1}+(-0.026055+3.004058) \varepsilon^{2}{ }_{\mathrm{t}-1}$

$\boldsymbol{\delta}_{\text {Pepper return }}=20.51134+0.178795 \delta_{\mathrm{t}-1}+(8.702471-8.057376) \varepsilon_{\mathrm{t}-1}^{2}$

The difference between good news and bad news, which is the coefficient of asymmetry term, is 3.004058 for Teff price Return and - 8.057376 for pepper price return. It is inferring to that there are asymmetries in the news, in which the bad news has larger effect on the volatility than the good news for both Teff and Red Pepper price returns. In finance theory, the relationship between risk and returns plays a pivotal role in asset pricing. If the risk is conditional and not constant over time, then the conditional expectation of the market returns is not only linear function of the conditional variance but also the information asymmetries too. Like financial time series, the leverage effect is exhibited in the return series of Teff and Red pepper prices. The result is consistent with findings of (Musunuru et al., 2013) and Le Roux, (2018) who asserts TGARCH model, also called GJR-GARCH, is the a best fit model for corn, coffee and cocoa, respectively, in which they assert the existence of leverage effect where negative shocks have a greater effect than positive one. In conclusion, the modeling of information, news or event is very significant determinant of assets volatility.

\section{Checking the Adequacy of the Fitted Models}

So far it has been mentioned that TGARCH was the best model for the series, diagnostic checking for this model employed to check the ARCH effect, serial correlation and normality. BreuschGodfrey serial correlation LM test was employed in order to check for possible ARCH effects on the residuals, Corrologram of standardized residual squared and Jarque - Bera for normality tests. Results are presented as follows: 


\section{Heteroskedasticity test}

Table 5: Heteroskedasticity Test: ARCH

$\begin{array}{llll}\text { F-statistic } & 0.006897 & \text { Prob. F (1,107) } & 0.9340 \\ \text { Obs*R-squared } & 0.007025 & \text { Prob. Chi-Square (1) } & 0.9332\end{array}$

Obs*R-squared $\quad 0.007025 \quad$ Prob. Chi-Square (1) 0.9332

Source: Author's own

From the results presented in Table 5, one can observe that the standardized residuals of the fitted model did not exhibit any additional ARCH effect for both series as both the F statistics and observed R squared are not significant.

\section{Test for serial correlation}

The null hypothesis states that there is no serial correlation in the residuals. It is implied that the statistical result of both the autocorrelation function (ACF) and partial autocorrelation function (PACF) lies within the confidence interval, and all the $\mathrm{p}$ value are more than $5 \%(0.05)$ or are not significant. It indicates that there is no serial correlation in the residuals; therefore, it fails to reject the null hypothesis

Finally even though the Jarque - Bera test statistic was significant, and hence, there was an evidence to reject the null hypothesis of normality, the selection of TGARCH $(1,1)$ model with Normal distributional assumption of residuals was well justifiable.

\section{Forecasting accuracy}

The second objective of the study was to predict price volatility of agricultural commodities. And following the selection of the best fit model and the diagnostic tests, an attempt was made to use the model for forecasting volatility of future series. The forecast performance of fitted GARCH family models was evaluated through the four conventional error measurements (forecast accuracy statistics): root mean square error (RMSE), mean absolute error (MAE), and Theil inequality coefficient and mean absolute percentage error (MAPE). The GARCH models with the lowest 
statistics were considered a better fit for modeling the conditional volatility of the price series. The summary results are displayed in Table 8 below.

Table 8 Evaluating forecast performance of fitted GARCH family models

\begin{tabular}{|c|c|c|c|c|c|c|}
\hline & & & $\underline{\text { Forecas }}$ & ccuracy & easure & \\
\hline & Model & Error Distribution & $\underline{\text { RMSE }}$ & $\underline{\text { MAE }}$ & Theil & MAPE \\
\hline Teff & $\operatorname{GARCH}(\mathbf{1}, \mathbf{1})$ & Normal distribution & 4.613 & 2.157 & 0.83088 & 136.36 \\
\hline & GARCH $(2,0)$ & Normal distribution & 4.693 & 2.16 & 0.84747 & 139.692 \\
\hline & $\operatorname{TGARCH}(\mathbf{1}, \mathbf{1})$ & Normal distribution & 4.603 & 2.157 & 0.82145 & 139.677 \\
\hline & $\operatorname{EGARCH}(\mathbf{1}, \mathbf{1})$ & Normal distribution & 4.606 & 2.186 & 0.83528 & 136.98 \\
\hline Pepper & $\operatorname{GARCH}(\mathbf{1}, \mathbf{1})$ & Normal distribution & 32.644 & 10.831 & 0.99 & 197.038 \\
\hline & GARCH $(2,0)$ & Normal distribution & 32.648 & 10.811 & 0.994 & 190.668 \\
\hline & $\operatorname{EGARCH}(\mathbf{1}, \mathbf{1})$ & Normal distribution & 32.663 & 10.848 & 0.995 & 165.515 \\
\hline & $\operatorname{TGARCH}(\mathbf{1}, \mathbf{1})$ & Normal distribution & 32.641 & 10.818 & 0.984 & 193.163 \\
\hline
\end{tabular}

In time series forecasting theory, one can do forecasting when the estimated model has no statistical problem, i.e. when there is no serial correlation, no heteroskedasticity and residuals are normally distributed. Since all these situations were satisfied, the model is ready for forecasting. From the table above, it is observed that TGARCH model has a better forecasting accuracy in both the in sample and out of sample forecast, since it possesses the smallest forecast error measures in the majority of the statistics.

\section{Conclusion}

The main objective of this study was to model and forecast price volatility for selected agricultural commodities in Ethiopia. Specifically, it aimed to identify the best fit GARCH Family models and predict price volatility of agricultural commodities in Ethiopia. To meet these objectives, monthly price data on Teff and Red pepper were collected from ANRSTMDB focusing on the data recorded from 2011 up to 2011. The actual price data of the commodities were transformed to $\log$ return series taking into account its better statistical properties. Enabling conditions for a financial time series data were considered in the analysis; for this purpose Akaike information criterion 
(AIC) and Schwarz information criteria (SIC) were applied for the selectin of appropriate model. Residuals were dragonized through Breusch-Godfrey serial correlation LM test for ARCH effects on the residuals, Corrologram of standardized residual squared for serial correlation on the residuals and Jarque - Bera for normality tests for normality on the residuals. Akaike information criterion (AIC) and Schwarz information criteria (SIC) were applied for the model selection purpose

The data analysis results showed that the price return series of Teff and Red Pepper demonstrated the characteristics of financial time series, such as leptokurtic distributions and volatility clustering which provides an adequate ground for the use of GARCH family models. Moreover, the presence of ARCH effects in the residuals of the conditional mean equation is supported by the ARCH-LM tests. In this study, both symmetric GARCH $(1,1)$, GARCH $(2,0)$ and asymmetric (EGARCH) and TGARCH models were considered in order to model the price return volatility of Teff and Red Pepper in the Ethiopian market.

Accordingly, based on the Akaika information Criteria and AIC and/or Schwarz information criteria (SIC), asymmetric TGARCH model with Normal distributional assumption of residuals was found to be a better fit for the price return volatility of Teff and Red Pepper. This implies that there is asymmetry in the news, in which the bad news has larger effect on the volatility than the good news for both Teff and Red Pepper price returns. In conclusion, as TGARCH is the better fit model for the Teff and Red Pepper price returns, modeling of information, news or event are very significant determinant of assets volatility.

Moreover, forecast performance of the model is evaluated using the mean squared error measurements such as RMSE, MAE, Theil inequality coefficient and MAPE in which it possesses the smallest forecast error measures in the majority of the statistics. Thus the accuracy of the TGARCH model was found to be good in forecasting price return volatility of Teff and Red Pepper.

In general, the findings of this study demonstrates that, TGARCH was the best fit model in modeling and forecasting price return volatility of Teff and Red Pepper, which suggests that market participants, whether they be farmers or investors, can get prepared for shifts in market momentum and in dealing with market choices. 
Reference

Abebe, T. H., Woldesenbet, E. G., \& Zeleke, B. L. (2020). Statistical Analysis of Price Volatility of Agricultural Commodities Traded at the Ethiopian Commodity Exchange (ECX) Using Multiplicative GARCH-MIDAS Two-component Model. Global Business Review, 0972150919895628.

Adugh, K. D. (2019). Modeling Volatility of Agricultural Commodity Food Price Index in Nigeria using ARMA-GARCH Models Modeling Volatility of Agricultural Commodity Food Price Index in Nigeria using ARMA-GARCH Models. 3(1), 55-75.

Arezki, R. (2012). Commodity price volatility and inclusive growth in low-income countries / editors, Rabah Arezki [and three others]. (R. Arezki \& International Monetary Fund (eds.)) [Book]. International Monetary Fund.

Ayele, A. W., Gabreyohannes, E., \& Tesfay, Y. Y. (2017). Macroeconomic Determinants of Volatility for the Gold Price in Ethiopia: The Application of GARCH and EWMA Volatility Models. Global Business Review, 18(2), 308-326. https://doi.org/10.1177/0972150916668601

Bollerslev, T. (1986). Generalized autoregressive conditional heteroskedasticity. Journal of Econometrics, 31(3), 307-327. https://doi.org/10.1016/0304-4076(86)90063-1

Engle, R. F. (1982). Autoregressive Conditional Heteroscedasticity with Estimates of the Variance of United Kingdom Inflation. Econometrica, 50(4), 987. https://doi.org/10.2307/1912773

Getnet, K. (2009). From auction market to Commodity Exchange: Managing coffee price risk in Ethiopia. Quarterly Journal of International Agriculture.

Lama, A., Jha, G. K., Paul, R. K., \& Gurung, B. (2015). Modelling and Forecasting of Price Volatility: An Application of GARCH and EGARCH Models. Agricultural Economics Research Review, 28(1), 73. https://doi.org/10.5958/0974-0279.2015.00005.1

Le Roux, C. L. (2018). Volatility Modelling of Agricultural Commodities: Application of Selected GARCH Models. 343-356. https://doi.org/10.1007/978-3-319-70055-7_27

Musunuru, N., Yu, M., \& Larson, A. (2013). Forecasting Volatility of Returns for Corn using 
GARCH Models. The Texas Journal of Agriculture and Natural Resources, 26, 42-55. http://txjanr.agintexas.org/index.php/txjanr/article/view/33

Nelson, D. B. (2011). Conditional Heteroskedasticity in Asset Returns : A New Approach Author ( $\mathrm{s}$ ): Daniel B . Nelson Published by: The Econometric Society Stable URL: http://www.jstor.org/stable/2938260 . CONDITIONAL HETEROSKEDASTICITY IN ASSET RETURNS : A NEW APPROACH. Society, 59(2), 347-370.

Pindyck, R. S. (2001). The dynamics of commodity spot and futures markets: A primer. Energy Journal, 22(3), 1-29. https://doi.org/10.5547/ISSN0195-6574-EJ-Vol22-No3-1

Rezitis, A. N., \& Sassi, M. (2013). Commodity Food Prices : Review and Empirics Commodity Food Prices : Review and Empirics. November 2015. https://doi.org/10.1155/2013/694507

Shiferaw, Y. A. (2012). Modeling Volatility of Price of Some Selected Agricultural Products in Ethiopia: Arima-Garch Applications. SSRN Electronic Journal, 1-13. https://doi.org/10.2139/ssrn.2125712

Thiyagarajan, S., Naresh, G., \& Mahalakshmic, S. (2015). Forecasting volatility in Indian agricommodities market. Global Business and Finance Review, 20(1), 95-104. https://doi.org/10.17549/gbfr.2015.20.1.95

Zakoian, J. M. (1994). Threshold heteroskedastic models. Journal of Economic Dynamics and Control, 18(5), 931-955. https://doi.org/10.1016/0165-1889(94)90039-6 